\title{
Hacia la construcción de un perfil para el docente del futuro
}

Walter Solano Gutiérrez

Jensy Campos Céspedes ${ }^{2}$

1. Universidad Estatal a Distancia, Costa Rica; wsolano@uned.ac.cr

2. Universidad Estatal a Distancia, Costa Rica; ycampos@uned.ac.cr

Recibido: 15 de octubre del 2014

Corregido: 05 de diciembre del 2014

Aceptado: 05 de diciembre del 2014

\section{Resumen}

El documento presenta los resultados de una investigación orientada a identificar las competencias claves que debe poseer el docente del futuro según la opinión de 911 estudiantes de carreras de Educación de la Universidad Estatal a Distancia de Costa Rica. La metodología consistió en la aplicación de una encuesta mediante la cual se les solicitó a los participantes indicar las cuatro competencias más importantes, que según ellos, debería poseer el docente para desempeñarse adecuadamente dentro de los siguientes 20 años. Las competencias mencionadas por los participantes fueron ordenadas según el sistema de clasificación de Villa y Poblete (2008) en el que se identifican 35 competencias genéricas, de ellas los participantes hicieron mención a 15 competencias y las cuatro más mencionadas fueron el uso de las tecnologías, el sentido ético, la orientación al aprendizaje y las relaciones interpersonales. Pese a la relevancia que parece tener las competencias mencionadas; los participantes dejan de lado competencias basales como las cognitivas y las lingüísticas.

Palabras clave: Perfil docente, competencias genéricas, percepción de estudiantes, docente del futuro, competencias del docente.

\section{Abstract \\ A construction approach of a profile for teachers of the future}

The document submits the results of an investigation oriented towards identifying the key competences a future teacher should have according to the opinion of the 911 students of the Education majors of the Universidad Estatal a Distancia de Costa Rica (Distance State University of Costa Rica). The methodology consisted in applying a survey where the participants were asked to indicate the four most important competences, which according to them, the teacher should have in order to perform adequately in the next 20 years. The competences mentioned by the participants were ordered according to the Villa and Poblete (2008) classification system where 35 generic competences are identified, of these the participants mentioned 15 competences and the four which were mentioned most were the use of technologies, the sense of ethics, orientation towards learning and interpersonal relations. Despite the relevance that the mentioned competences seem to have, the participants left aside base competences such as the cognitive and linguistic ones.

Key words: Teacher profile, generic competences, students' perception, future teachers, teacher competences. 


\section{INTRODUCCIÓN}

La discusión sobre posibles escenarios para el desarrollo de la educación es un tema recurrente en la bibliografía actual dentro del campo educativo. Uno de los aspectos cruciales en los escenarios futuros se refiere al tipo de competencias que esos escenarios demandarán para los profesionales de la educación. La ideación de perfiles profesionales que permitan preparar el recurso humano idóneo para el desempeño exitoso en la educación, es uno de los retos que las unidades formadoras de docentes y la sociedad en general afronta en este momento.

El perfil profesional del docente exige competencias que logren satisfacer no solo las exigencias del mercado sino las necesidades de los diferentes sectores sociales y contribuir al cumplimiento de las aspiraciones de desarrollo de la sociedad. De allí la importancia de que el perfil profesional contenga no solo competencias específicas, sino también competencias genéricas orientadas a la conformación de un profesional integrado y no centrado solamente en la productividad (Fernández y Salinero, 2006; Villa y Poblete, 2008). El desarrollo de las competencias genéricas en los profesionales de la educación resulta especialmente importante cuando se consideran los cambios de las nuevas sociedades, caracterizadas por creciente desigualdad y exclusión social, intensos fenómenos migratorios, relativismo ideológico, omnipresencia de los medios de comunicación social, globalización económica e ingobernabilidad, entre otros.

De acuerdo con Villa y Poblete (2008), "una competencia genérica o trasversal no debe disociar el conocimiento de los valores y actitudes de su uso. Contrariamente, debe integrar el conocimiento con las habilidades personales y sociales y considerarlo desde el punto de vista ético y social. Aprendemos y nos desarrollamos no únicamente para beneficio personal sino también para el desarrollo y beneficio de los demás" (p.44). En este sentido, al integrar dentro de los perfiles profesionales no solo las competencias específicas sino también las competencias genéricas, se facilita en la formación profesional la integración de los valores, actitudes y responsabilidades necesarios para responder a las características del siglo XXI.

La construcción de un perfil profesional del docente es un ejercicio no solo imprescindible para orientar la formación inicial sino también para enriquecer los procesos de desarrollo profesional, o el aprendizaje a lo largo de la vida que los educadores en ejercicio deben realizar. El uso del modelo por competencias para la elaboración de un perfil profesional permite la identificación de diferentes saberes, quehaceres, actitudes y valores que se materializan en características de las personas para la realización de un buen desempeño en contextos determinados.

El concepto de competencia es polisémico y multidimensional, por lo que existe una multiplicidad de definiciones y una gran dificultad para identificar un criterio unificado o una conceptualización única. Rodríguez, Serreriy Del Cimmut (2010) realizan una clasificación del concepto de competencias de acuerdo con el enfoque en el cual se utiliza. Así, se tienen enfoques racionalistas, orientados al trabajador, orientados al trabajo, multi-métodos, holísticos e interpretativos.

Por otra parte, Torrelles, Coiduras, Isus, Carrera, París y Cela (2011) señalan que múltiples autores ponen en evidencia el carácter multidimensional de la competencia, como una combinación de saberes, técnicas, actitudes, dispositivos y comportamientos orientados hacia la actividad profesional. Bunk (1994) ilustra esta multidimensionalidad proponiendo cuatro clases de competencias: técnicas (el saber), metodológicas (el saber hacer), personales (saber ser), y sociales (saber participar).

Entre las múltiples definiciones de competencias se encuentran la de Zabla y Arnau (2010) para quien el concepto de competencias hace alusión a la capacidad de efectuar tareas o hacer frente a situaciones diversas de formar eficaz en un contexto determinado mediante la movilización de actitudes, habilidades y conocimientos simultánea e interrelacionadamente (p. 43).

Pese a lo multiplicidad de definiciones en torno a la palabra competencia, existe consenso en que los contenidos elementales implicados en una competencia son: saber, saber hacer, saber ser y saber estar. 
Para efectos de la investigación de la que da cuenta este documento se adopta la definición planteado por Villa y Poblete (2008), "entendemos por competencia el buen desempeño en contexto diversos y auténticos basados en la integración y activación de conocimientos, normas, técnicas, procedimientos, habilidades y destrezas, actitudes y valores" (p. 24).

En este trabajo se presenta una propuesta de perfil profesional del docente basado en competencias y generado a partir de la opinión de estudiantes de carreras de educación de la Universidad Estatal a Distancia de Costa Rica.

\section{METODOLOGÍA}

La investigación corresponde a un estudio basado en encuesta mediante el cual se identificaron las competencias claves del perfil profesional para el docente del futuro, a partir de la opinión de estudiantes de carreras de Educación.

La población del estudio estuvo constituida 911 estudiantes quienes estaban matriculados, durante el segundo cuatrimestre del 2013, en las de asignaturas de las carreras de la Escuela de Ciencias de la Educación. En cuanto a las características sociodemográficas de los participantes se encontró que el $83,5 \%$ son mujeres y $16,5 \%$ hombres. El $58 \%$ son personas entre los 19 y 30 años de edad, el 30,2\% tienen entre 31 y 42 años de edad y el restante 12 , $6 \%$ tiene más de 43 años de edad y solamente 0,2 $\%$ tiene menos de 18 años. El 57,7 \% de los participantes contaban con nivel de bachiller en educación media al ingresar a la universidad mientras que un $42.3 \%$ tiene algún grado universitario a nivel de grado o posgrado. En cuanto a la carrera que cursan los participantes, el 42,3\% es de Educación General Básica I y II Ciclos; el 23,7\% de Educación Preescolar; el 17,2\% de Licenciatura en Docencia; el 5,5\% de Educación Especial, el 4,9\% de Informática Educativa, el 4,4\% de Administración Educativa, 2\% de Estudios Sociales y Educación Cívica. Respeto a la experiencia profesional de los participantes, 63\% no tiene experiencia y $37 \%$ sí tiene experiencia; de los participantes que tienen experiencia docente más del 62,02\% tiene menos de 5 años; $19,8 \%$ tiene de 6 a 11 años y 18,10\% tiene más de 12 años.
La información se obtuvo mediante la aplicación de una encuesta en línea en la que se les solicitó a los participantes indicar las cuatro competencias esenciales para el exitoso desempeño del profesional de la educación en el futuro. A partir de ese ejercicio, se obtuvo un total de 1002 enunciados referentes a competencias que los participantes consideraban que deberían poseer los docentes para desempeñarse de manera pertinente en escenarios educativos, dentro de los próximos 20 años.

La totalidad de los 1002 enunciados ofrecidos por los participantes fue, en un primer momento, agrupada según nivel de afinidad entre los mismos. Con ello, se obtuvieron varios grupos de enunciados, que posteriormente fueron categorizados de acuerdo con el ordenamiento propuesto por Villa y Poblete (2008) con ajustes o adaptaciones a las definiciones brindadas por ellos en algunas de las competencias.

El ordenamiento de Villa y Poblete (2008), utilizado para categorizar los enunciados de los participantes, implica la organización de competencias en tres clasificaciones: instrumentales, interpersonales y sistémicas. La clasificación "instrumentales" comprende cuatro categorías de competencias, a saber: las cognitivas, las metodológicas, las tecnológicas y las lingüísticas. En cuanto a la clasificación "interpersonal" se integran las competencias dentro de dos categorías: individuales y sociales. Finalmente, la clasificación "sistémica" comprende las categorías de organización, capacidad emprendedora y liderazgo.

En la clasificación de competencias instrumentales se encuentran las competencias cognitivas que incluyen pensamiento analítico, sistémico, crítico, reflexivo, lógico, analógico, práctico, colegiado y deliberativo. La categoría metodológica incluye gestión de tiempo, resolución de problemas, toma de decisiones, orientación al aprendizaje y planificación. La categoría de competencias tecnológicas incluye el uso de las TIC y la utilización de bases de datos, mientras que la categoría de competencias lingüísticas comprende la comunicación verbal, la comunicación escrita y el manejo de idioma extranjero. 
Para las competencias de la clasificación "interpersonales", se establecen dos categorías: individuales y sociales. Las primeras incluyen automotivación; diversidad e interculturalidad; resistencia y adaptación al entorno; sentido ético. Las segundas, es decir las sociales, incorporan comunicación interpersonal, trabajo en equipo, tratamiento de conflicto y negociación.

La clasificación "sistémica" se subdivide en las siguientes categorías: organización, capacidad emprendedora y liderazgo. En la categoría organización se ubican las competencias gestión por objetivos, gestión de proyectos y orientación a la calidad (esta última para efectos de este estudio ha sido denominada actualización y capacitación). La categoría capacitad emprendedora integra las competencias: creatividad, espíritu e innovación. Finalmente, la categoría liderazgo contempla la orientación al logro y el liderazgo.

Como se indicó anteriormente, se asumió el listado de competencias de la Universidad de Deusto, sistematizada por Villa y Poblete (2008). No obstante, algunas de las competencias propuestas por ellos, se ampliaron para este estudio, incluyendo otros indicadores o componentes que se consideraron necesarios. Esta adaptación se realizó específicamente para el caso de la competencia orientación a la calidad, la cual se reemplazó por actualización y capacitación. Asimismo, en cuanto a la competencia sobre uso de las TIC, se incorporó no solo el uso de computadoras y de Internet sino también de dispositivos móviles, bases de datos y herramientas de la web 2.0 y 3.0 .

Una vez categorizados los enunciados ofrecidos por los participantes de acuerdo con el ordenamiento de Villa y Poblete (2008), se encontró que las competencias más relevantes según ellos son el uso de las tecnologías, el sentido ético, la actualización y capacitación y la comunicación interpersonal. No obstante, esas competencias se complementan con otras señaladas por los participantes, utilizando como criterio arbitrario la inclusión de aquellas que alcanzaron un número igual o mayor a siete menciones, de tal suerte que el perfil del docente del futuro se completaría mediante la integración de las competencias de resistencia y adaptación al entorno, creatividad, innovación, liderazgo, manejo de idioma extranjero, diversidad intercultural, pensamiento crítico, tratamiento de conflictos y pensamiento analítico.

\section{RESULTADOS}

Los datos aportados por los participantes de la investigación se ordenaron siguiendo el modelo de organización de las competencias de Villa y Poblete (2008) y su procesamiento estadístico se resume el tabla número 1 .

Como puede observarse, las competencias que fueron mayormente mencionadas por los participantes obedecen a la categoría de competencias instrumentales. No obstante, esas competencias se concentran en competencias metodológicas y tecnológicas, mientras que para las cognitivas solamente se señalan datos en cuanto al pensamiento analítico y pensamiento crítico; quedando ausentes las demás competencias cognitivas. Dentro de la categoría de competencias interpersonales, el sentido ético, la comunicación interpersonal y la resistencia, así como la adaptación al entorno, son las que ocupan mayores menciones por los participantes como competencias relevantes para el desempeño en el futuro de los docentes. Finalmente, en cuanto a las competencias sistémicas, las que ocupan mayor número de menciones son las competencias relacionadas con la creatividad y la actualización y capacitación.

El mayor peso de las menciones se concentra en la clasificación del grupo de competencias instrumentales con un $42,3 \%$. En segundo lugar, con un $34,7 \%$, se ubica la clasificación de competencias interpersonales y, en tercer lugar, aparece la clasificación de competencias sistémicas con un $23 \%$.

En la categoría de competencias instrumentales que son aquellas que tienen "una función de medio o herramienta para obtener un determinado fin" (Villa y Poblete, 2000, p. 49), las competencias que fueron menos mencionadas por los participantes son las cognitivas, con solo un $5 \%$ de las menciones. En comparación, las lingüísticas tienen un $8,5 \%$; las metodológicas, un $25 \%$ y las tecnológicas, un $61 \%$. Se destaca, en estos datos, la baja cantidad 
TABLA 1

Organización de competencias propuestas por los participantes, según el listado de Villa y Poblete (2008).

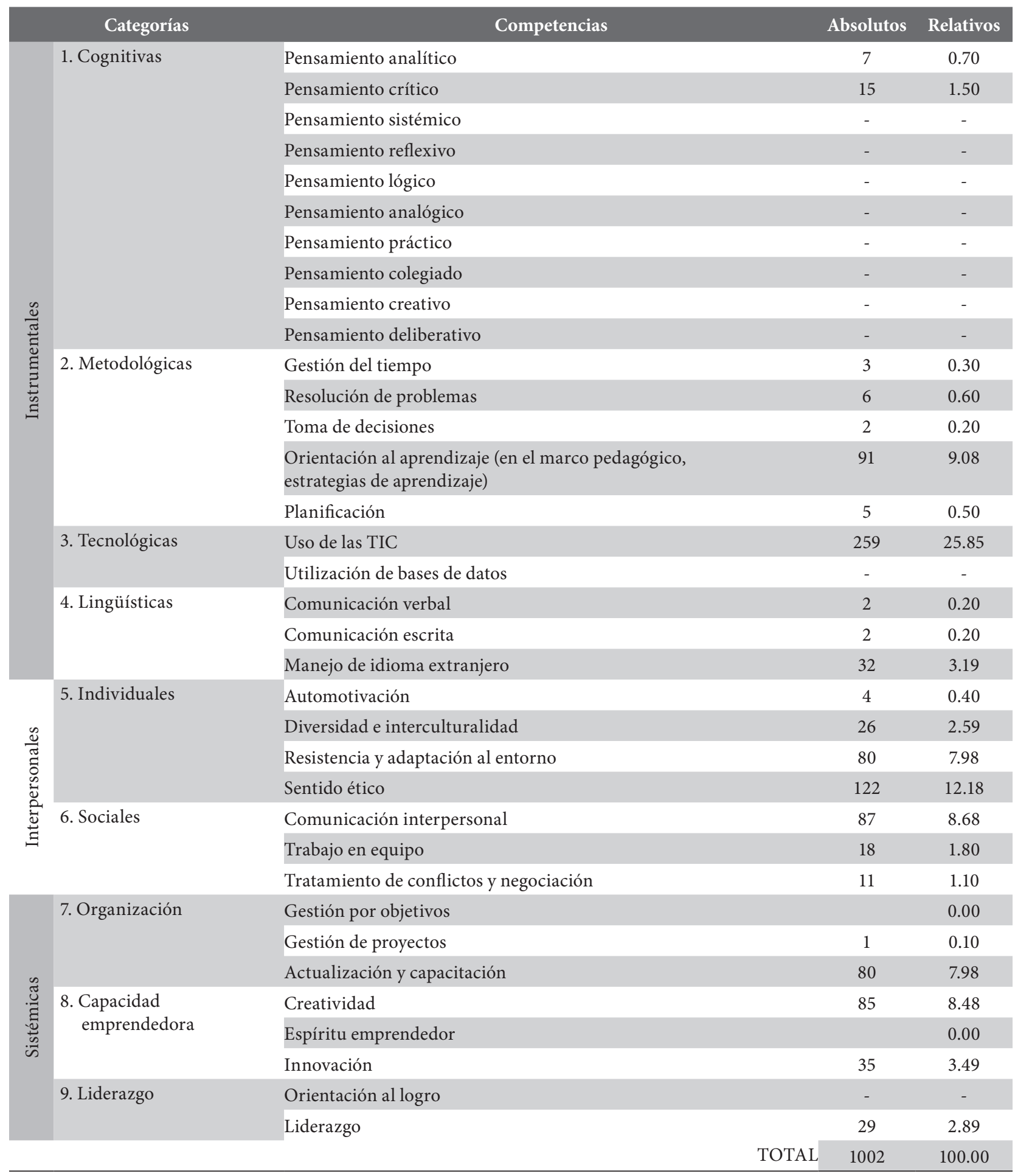


de participantes que hicieron mención a las competencias cognitivas y lingüísticas siendo este tipo de competencias básicas y claves para el desarrollo integral de las personas y, especialmente, para el desempeño docente en los nuevos contextos educativos.

En la figura 1 se observa el perfil del docente futuro construido a partir de las opiniones de los participantes.

\section{DISCUSIÓN Y ANÁLISIS DE LAS COMPETENCIAS CITADAS POR LOS PARTICIPANTES EN EL ESTUDIO}

\section{- Competencias cognitivas}

Las competencias cognitivas se refieren al desarrollo de habilidades y destrezas para aprender

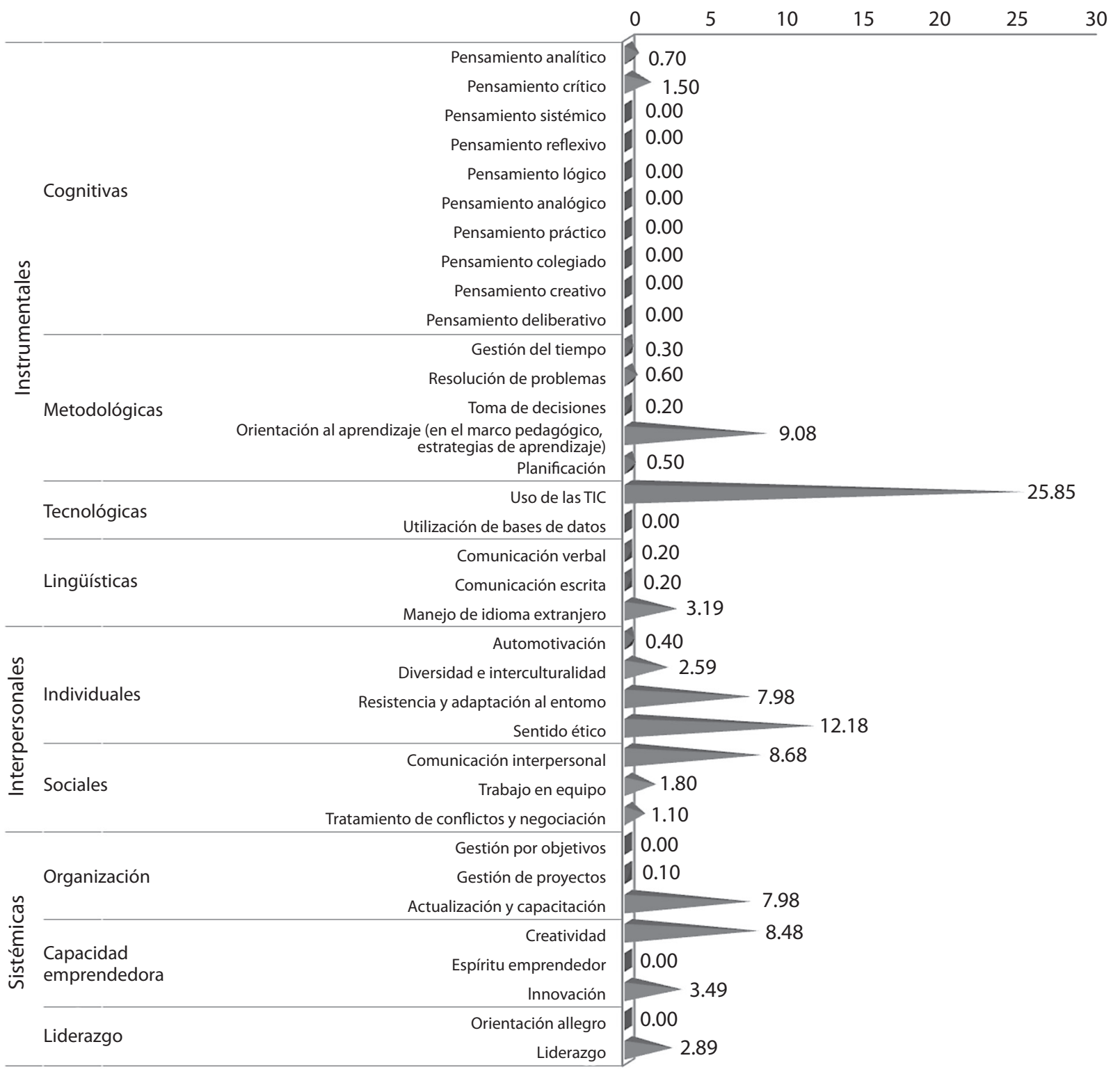

Figura 1. Organización según, clasificación, categorías y competencias que debe presentar el perfil del docente de acuerdo con la opinión de participantes. Fuente: Encuesta a participantes del estudio, 2013. 


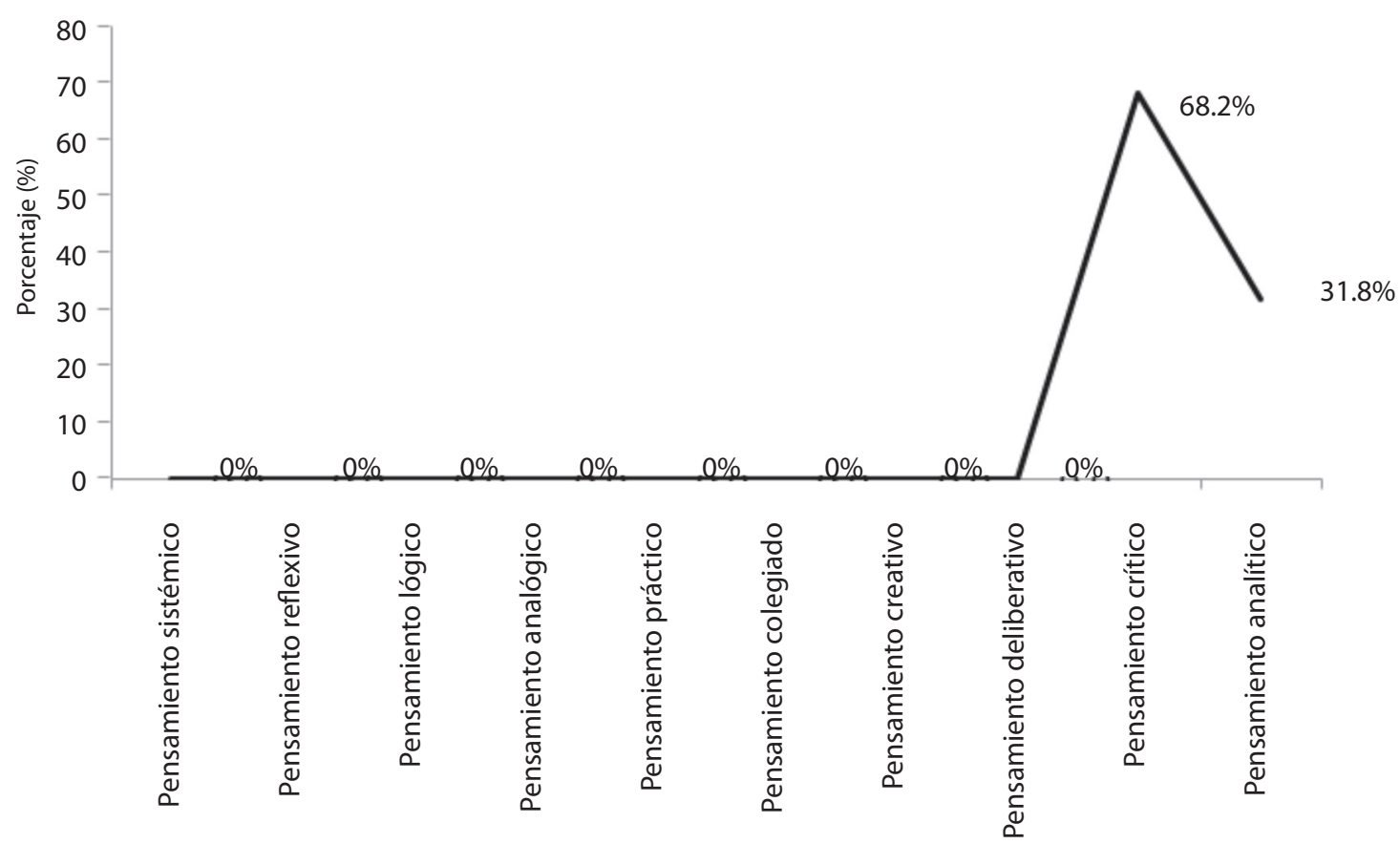

Figura 2. Distribución de competencias categorías de competencias que debe presentar el perfil del docente, según opinión de participantes. Fuente: Encuesta a participantes del estudio, 2013.

a pensar. "El pensamiento es un concepto que se puede entender, en un sentido general, como 'todas la actividades cognitivas inteligentes' (Erickson y Hastie, 1994, p.37), o 'todo lo que media entre la percepción y la acción' (Jonhnson-Laid, 1993, p. xi). También lo podemos definir como un mecanismo de adquisición de conocimiento" (Saiz, 2008).

En este estudio, la categoría competencias cognitivas alcanzó un total de 22 menciones. De ellas, 15 menciones se refirieron a la competencia pensamiento crítico y 7 hicieron alusión al pensamiento analítico. El resto de las competencias no alcanzaron ninguna mención, tal como se observa en la figura 2.

De acuerdo con estos datos, pareciera que los participantes del estudio desestiman la importancia en los procesos de aprendizaje de las competencias cognitivas. La era de la información y el "conocimiento" exige habilidades y destrezas del pensamiento para cribar el trigo de la paja. Saiz (2008) al respecto dice:

El desarrollo informático y facilidad de acceso a la "red de redes", permite que cualquier persona con un modesto ordenador y un módem pueda consultar decenas de bases de datos, o acceder a información que no hace mucho suponía meses de trabajo. El exceso de información que existe es un inconveniente si no se dispone de buenos filtros que dirijan nuestra atención a lo realmente importante (p. 56).

El pensamiento crítico y el pensamiento analítico y las demás competencias cognitivas son actividades intelectuales de la mente que, educadas y formadas por los procesos de enseñanza y aprendizaje, permitirían tamizar la vorágine de información que caracteriza las nuevas sociedades. Por tanto, son competencias basales que deben poseer las personas, especialmente los profesionales.

Edward De Bono (2011) afirma que "enseñar pensamiento debería ser la preocupación principal en la educación. Nada es más importante para la vida personal, la vida profesional y para la contribución a la sociedad" (p. 155). La tendencia social al acrecentamiento exponencial de información exige de los profesionales identificar, evaluar y seleccionar información de calidad. De allí que, tal como lo indica Hawes (2003), desarrollar el pensamiento crítico es 
un compromiso mayor de la formación universitaria y una expectativa social sobre los profesionales que ella gradúa para una sociedad no existente aún pero que se gesta a partir de la complejidad y la sobresaturación informativa. Según el Institute Forthe Future, la habilidad para traducir inmensas cantidades de datos en conceptos abstractos y saber encontrarle aplicabilidad práctica es uno de los dominios más importantes que deberán poseer los trabajadores en el futuro y esta técnica está ligada directamente con las competencias cognitivas. Pese a todas esta consideraciones, tanto intelectuales como prácticas, de 1002 menciones solamente 22 se refieren a las competencias cognitivas y únicamente hacen referencia al pensamiento analítico y al pensamiento crítico (7 y 15 menciones respectivamente).

El desconocimiento de la relevancia para los procesos de aprendizaje de esta competencia, por parte de los formadores, podría radicar en que "aprender a pensar" se alcanza únicamente con la aprehensión de los distintos contenidos disciplinarios de los programas de estudio. No obstante, existen posturas académicas que sostienen que si no se enseñan no se aprenden. Esta posición presupone que las competencias como el pensamiento crítico, analítico, lógico y creativo, entre otros, bien pueden constituirse en contenidos para su correspondiente enseñanza en los diferentes niveles educativos.

Las competencias cognitivas, sobre todo el pensamiento analítico y crítico, deben ser consideradas como praxis, de manera que permitan a las personas construir conocimiento, tanto para el desarrollo profesional como para el personal, es decir, enseñar a aprender a vivir.

\section{- Competencias metodológicas}

La segunda categoría de las competencias está constituida por las competencias instrumentales. Estas involucran tres diferentes subgrupos, a saber, las metodológicas, las tecnológicas y las lingüísticas. Tal como se observa en la figura 3, las competencias instrumentales más mencionadas por los participantes son, en primer lugar, las tecnológicas; en segundo lugar, las metodológicas y en tercer lugar, las comunicativas. En este sentido, las competencias que alcanzaron valores significativos fueron las de uso de las tecnologías, la orientación al aprendizaje y el manejo de idioma extranjero, el resto de las menciones fueron inferiores a 6 dentro del total de 100 .

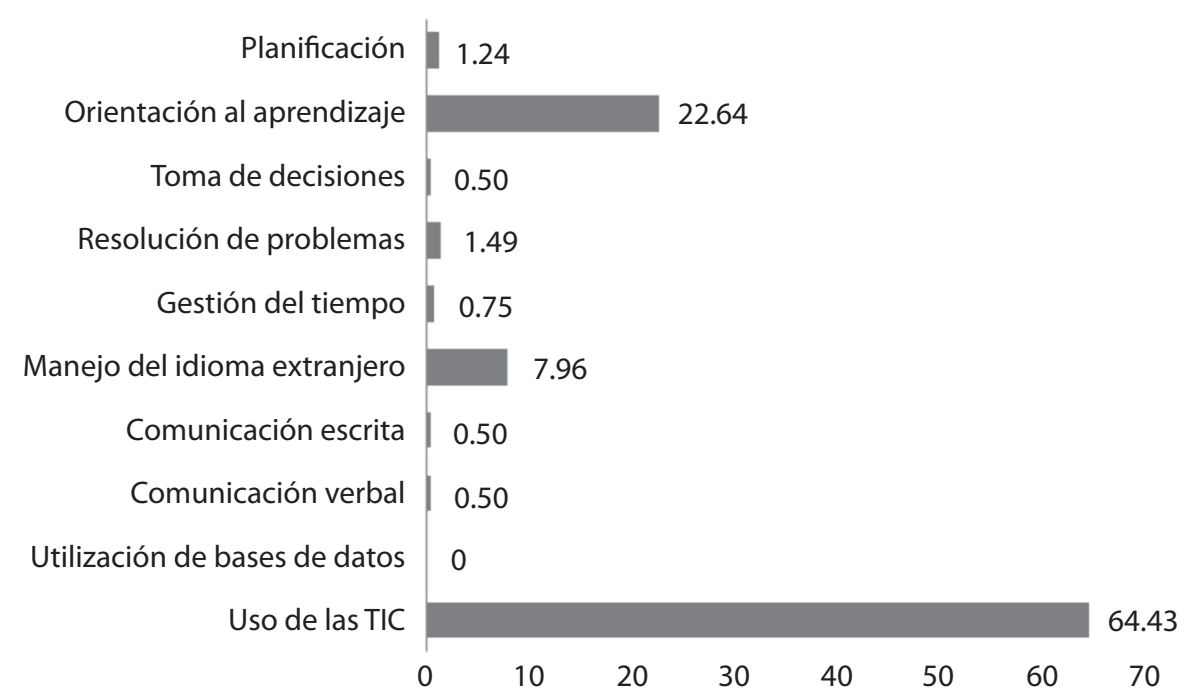

Figura 3. Distribución de competencias instrumentales que debe presentar el perfil del docente, según opinión de participantes. Fuente: Encuesta a participantes del estudio, 2013. 


\section{- Competencias instrumentales: orientación al aprendizaje}

El segundo subconjunto de competencias instrumentales, según el modelo asumido para el estudio, está constituido por las competencias metodológicas que involucran la gestión del tiempo, resolución de problemas, toma de decisiones, orientación al aprendizaje y planificación. Las menciones de los participantes en ese grupo se presentan en la figura 4 y la mayor cantidad de menciones se concentran en la competencia denominada orientación al aprendizaje. Esa competencia se entiende como los dominios que permiten a las personas "utilizar el aprendizaje de manera estratégica y flexible en función del objetivo perseguido, a partir del reconocimiento del propio sistema de aprendizaje y de la conciencia del aprendizaje mismo" (Villa y Poblete, 2008, p. 153).

Pese a que el listado se refiere a competencias genéricas, la valoración de esta competencia por parte de los participantes se asumió como competencias específica, ello en virtud de que el aprendizaje es parte del quehacer sustantivo de su formación profesional.
Los indicadores aportados por los estudiantes para justificar la competencia orientación al aprendizaje parecen avanzar más allá de un aprendizaje reproductivo. Se observan, por ejemplo, aseveraciones como: "aprender a desaprender para aprender"; "ser facilitador de la construcción de conocimiento"; "enseñar aprendiendo y aprender a enseñar"; "facilitar experiencias de aprendizaje y herramientas para afrontar la realidad"; "actitud hacia la actualización de la información dando énfasis al aprendizaje de manera lúdica"; "preparar a los estudiantes con conocimiento significativos para sus vidas y no solo materia extra"; "habilidad para enseñar a cualquier personas con necesidades educativas especiales";"aprender a conocer; aprender a aprender, a convivir y aprender a ser"; "aprender a conocer, aprender a aprender, a convivir y aprender a ser"; "habilidad para dirigir grupos para el aprendizaje en común"; "realizar un proceso de enseñanza aprendizaje donde el estudiante sea el que construya su propio conocimiento"; "preparar alumnos para que aprendan a pensar, investigar $y$ desarrollarse como un ser integral".

Estas manifestaciones exteriorizadas por los participantes del estudio enuncian la necesidad de que el docente del futuro se distancie de modelos de

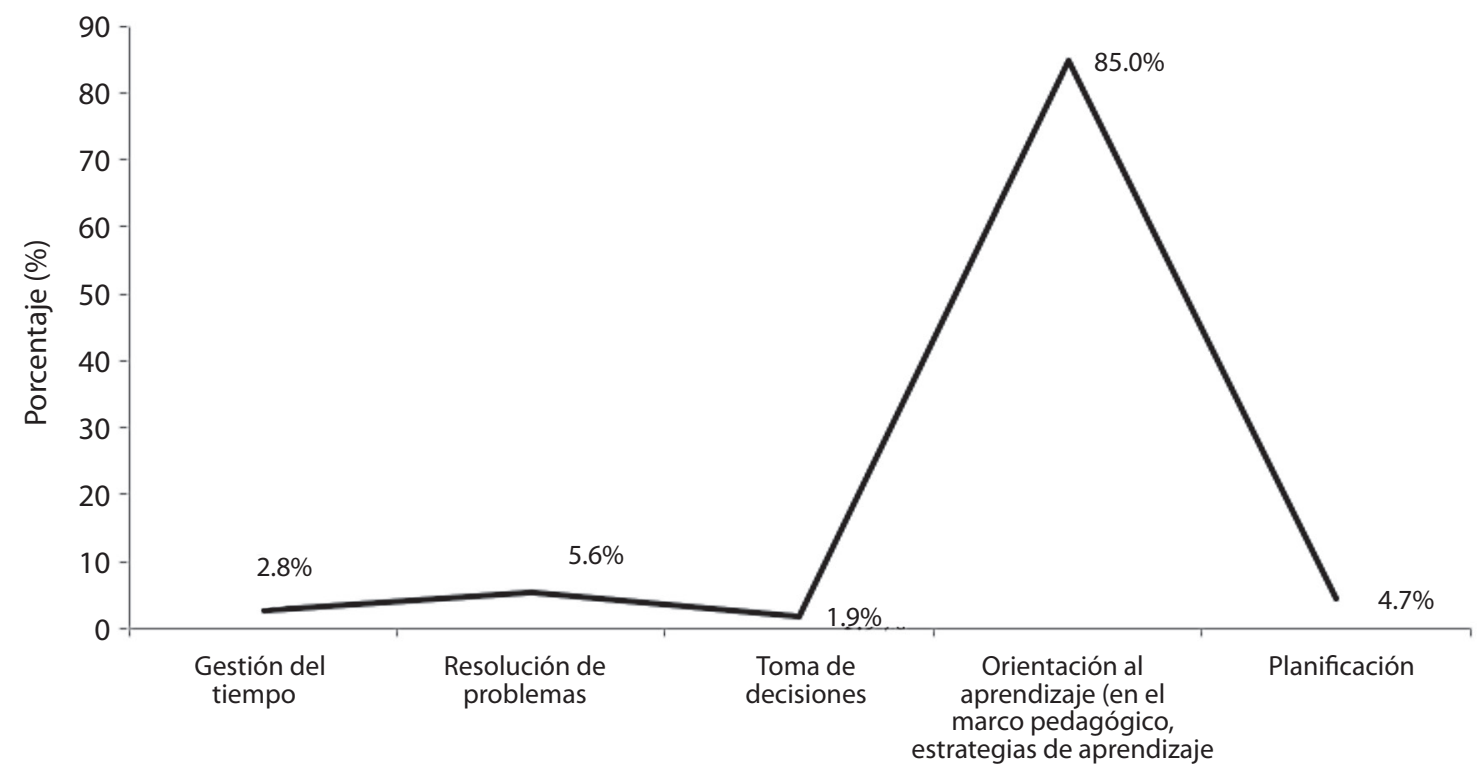

Figura 4. Distribución de competencias metodológicas que debe presentar el perfil del docente, según opinión de participantes. Fuente: Encuesta a participantes del estudio, 2013. 
enseñanza-aprendizaje reproductivos y asuma un enfoque que le permita migrar hacia modelos en los que se ubique el aprendizaje como una habilidad que exige la construcción del conocimiento.

Esto implica no solo la comprensión de los aspectos cognitivos, sino también los elementos emocionales que influyen en el proceso de aprendizaje. Las emociones juegan un papel preponderante en el desarrollo de conocimientos, tal como lo indica Bach y Darder (2002): "El conocimiento de la realidad no se realiza en frío, sino en caliente, es decir, al mismo tiempo que conozco, experimento y asocio sentimientos de placer o de dolor, de satisfacción o de insatisfacción, de atracción o de repulsión hacia aquello que conozco" (p. 70).

En consecuencia, los profesionales de la educación en el futuro deberían considerar como elemento esencial el binomio cognición- emoción en el desarrollo formativo, pues la ausencia de uno de esos elementos inhabilita la efectividad del proceso educativo y limita la formación integral de los educandos.

La competencia orientación al aprendizaje es indispensable, no solo en los profesionales de la educación, sino a lo interno de toda la sociedad. Esto ocurre en razón al fenómeno de traslación de una sociedad de la información a una sociedad del conocimiento y del aprendizaje, período en el que el aprendizaje permanente reclamará un papel clave, y la habilidad más competitiva será el aprender y la inteligencia, la materia prima por excelencia.

La competencia orientación al aprendizaje se determina como apremiante en un mundo en donde prevalece en fenómeno de la obsolescencia de la información, consecuencia del crecimiento exponencial del conocimiento científico y tecnológico. Este acontecimiento exige el aprender a aprender como acción permanente a lo largo de la vida, no solo profesional, sino también personal.

\section{- Competencias tecnológicas}

En cuanto a la categoría de competencias tecnológicas, la que alcanzó el mayor número de menciones fue la competencia sobre uso de las TIC, con 259 de las 1002 referencias registradas. Es una de las competencias considerada como clave para la conformación de un perfil profesional del docente del futuro, según los participantes del estudio.

La incorporación de la competencia "uso de las TIC" en el perfil profesional es decisivo pues, efectivamente, el desarrollo de las tecnologías y su imbricación en la cotidianidad exige las destrezas para su uso, en la búsqueda, organización, sistematización de la información que pueda ser procesada al extremo de generar conocimiento. Esto se logra, como afirma Morín, "en tanto es organización, relación y contextualización de la información” (p.17). La información proveniente de todas partes y de todo tipo de medio nos invade, acosa y hasta entorpece en todas las dimensiones de la vida. Su aprehensión para la producción de conocimiento exige la puesta en acción de competencias cognitivas.

En este sentido, se tienen pronunciamientos de diferentes autores. La UNESCO, por ejemplo, plantea la necesidad de contar con competencias en el uso de las tecnologías para los docentes. De acuerdo con este organismo, las competencias en TIC se clasifican en las competencias básicas de alfabetización digital, las competencias de aplicación y las competencias éticas (UNESCO citado por Arras, Torres y García Valcárcel, 2008).

En las menciones realizadas por los participantes, las competencias sobre uso de las TIC parecen relacionarse con las competencias clasificadas por la UNESCO como competencias básicas de alfabetización digital, es decir, están centradas en la aplicación de herramientas para obtener información así como el uso y elaboración de materiales utilizando fuentes de la Internet.

Algunas de las manifestaciones expresadas por los participantes en torno al uso de las TIC son las siguientes: "tecnologías de la información"; "manejar a la perfección las computadoras y navegar en internet"; "tener conocimientos y habilidades en el uso de la tecnología y manejar grupos virtuales y no solo dar clases en el aula"; "uso adecuado y oportuno de la tecnología digital"; "creativo dominio total de las tecnologías inteligentes" ;"habilidades para utilizar 
paquetes informáticos en la práctica pedagógica"; "experiencia en el manejo de todo tipo de dispositivos tecnológicos"; "utilizar las tecnologías como técnica para llevar a cabo el aprendizaje"; "actitud abierta al uso de las tic".

Fueron muy pocas las menciones que hacen alusión a las competencias de aplicación y las competencias éticas en el uso de las TIC. De las menciones citadas por los estudiantes en cuanto a estas dos categorías de competencias sobre las TIC, se identificaron las siguientes: "aprovechamiento de las herramientas informáticas", "uso de las tic para construir conocimientos", "conocer sobre tecnologías que permitan realizar un trabajo conjunto".

Si se piensa en una proyección hacia el futuro en cuanto a la formación docente en este campo, la concentración de las menciones en las competencias básicas de alfabetización digital, es una limitación, pues si bien los docentes deben tener un alto dominio de lo que supone la alfabetización digital, es necesario trascender ese nivel, de manera que se logre utilizar las tecnologías para resolver problemas en situaciones del mundo real, colaborar con otros y hacer uso de las redes de acceso a la información y a los expertos así como demostrar uso ético, legal y responsable de las TIC (Arras, Torres y García Valcárcel, 2008, p. 4).

En lo concerniente al campo de la formación profesional docente, no estaría de más reiterar que la tecnologías son medios, es decir vehículos, y que por sí solas no "median" didácticamente los contenidos en los procesos de enseñanza aprendizaje. La mediación didáctica de los contenidos de aprendizaje es -en todo caso- responsabilidad de la participación efectiva de los actores educativos. ¡ El medio no es el maestro!

\section{- Competencias lingüísticas}

La categoría lingüística incluye las competencias verbal, escrita y el manejo de idioma extranjero (Villa y Poblete, 2008). De las 1002 menciones de los participantes en el estudio, dos corresponden a la comunicación escrita y dos a la comunicación verbal. El dato es en sí insospechado, ya que las habilidades comunicacionales son indispensables para el adecuado desempeño de los profesionales e, incluso, determinantes en el desarrollo de procesos de aprendizaje.

La oralidad o el desarrollo del leguaje es un elemento clave en el aprendizaje pues permite la interacción y el intercambio de ideas y significados que propician la incorporación y creación de nuevos conocimientos. La comunicación oral es en sí una competencia pero a la vez el medio por el cual se potencia el desarrollo de aprendizajes y la expansión del bagaje conceptual y las redes de significados en los individuos. De igual manera, la competencia referida a la comunicación escrita es básica porque permite el desarrollo de una multitud de circuitos neuronales que dan lugar a otras competencias y están asociadas con la internalización y exteriorización de información, la creación de significados y, en general, la creación de la infraestructura intelectual.

En la formación profesional, en ocasiones se da por sentado que los estudiantes que ingresan poseen competencias en la comunicación escrita (por lo tanto, en la lectura) y en la comunicación verbal (y como consecuencia lógica, en la escucha). Habitualmente se presume que el ingreso del estudiante al contexto universitario implica necesariamente que este posee las competencias lecto-escriturales requeridas para el exitoso desarrollo de su proceso de aprendizaje, ignorando de esa manera una realidad que algunos autores e incluso organismos internacionales denuncian: el déficit lecto-escritural, el bajo nivel de habilidades para la escucha activa e incluso el analfabetismo funcional. Estas condiciones se exacerban con la cultura icónica que se expande mediante el desarrollo de las tecnologías y de las nuevas sociedades fuertemente influidas por la industria mediática y audiovisual (Castañeda, 2011; Fregoso, 2010).

El desarrollo de las competencias lingüísticas, al igual que otras competencias genéricas, no se acaba con la conclusión de los procesos de educación primaria y secundaria, sino que su formación debe ser continuada a lo largo de la educación universitaria e, incluso a lo largo de la vida, pues al igual que las competencias cognitivas son competencias basales. Los datos del estudio revelan que los estudiantes participantes no consideran la comunicación oral 
y escrita como competencias esenciales para los futuros profesionales de la educación, caso contrario a la competencia lingüística referida al manejo de idioma extranjero, donde los participantes hicieron 32 menciones.

Según los participantes del estudio, el manejo de un segundo idioma por parte de los profesionales de la educación es una competencia imprescindible para desempeñarse adecuadamente en los nuevos escenarios educativos. En este sentido, y frente a la tendencia a la globalización de las sociedades, existen razones irrefutables por las cuales el manejo de un segundo e incluso de un tercer idioma por parte de los profesionales se perfila como uno de los haberes más preciados en las nuevas sociedades, pues amplifica el abanico de oportunidades y expande el intercambio intercultural. De allí que el dominio de otros idiomas, adicionales a la lengua materna, sea uno de los aspectos que requieren ser fortalecidos en los procesos educativos, pues el dominio de las lenguas no solo brinda oportunidades en el campo laboral o profesional, sino en la comprensión y la aprehensión de los valores implícitos en otras culturas. El dominio de otros idiomas es, entonces, no solo una competencia lingüística sino también una competencia intercultural altamente requerida en los actuales contextos en los que las fronteras sociales se desdibujan.

\section{- Competencias interpersonales. Dimensión individual}

En lo referente a la clasificación de competencias interpersonales los participantes ofrecen cerca de 300 menciones. No obstante, la mayoría de las menciones se concentran en la categoría individual, tal como se observa en la figura 5 .

Dentro de la clasificación de competencias interpersonales, la categoría "individuales" alcanza el mayor número de menciones y se ordena según se describe en la figura 6, siendo el sentido ético y la resistencia y adaptación al entorno, las dos competencias con mayores menciones.

En cuanto a la competencia interpersonal individual denominado sentido ético, los participantes

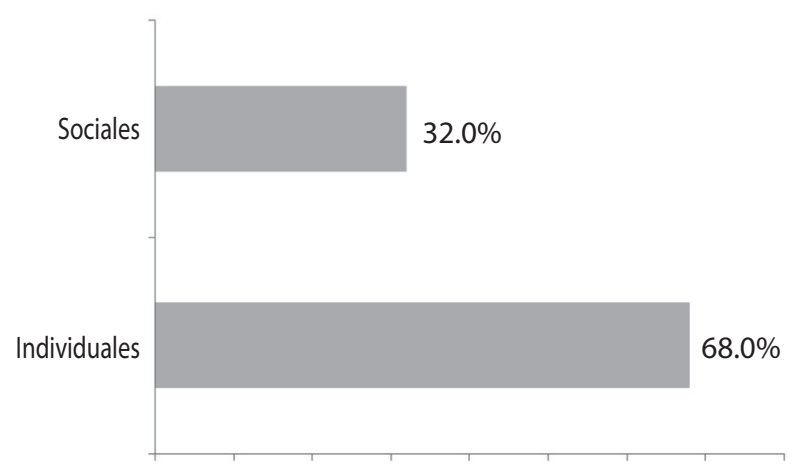

Figura 5. Distribución de la clasificación de competencias interpersonales propuestas para el perfil del docente, según opinión de participantes. Fuente: Encuesta a participantes del estudio, 2013.

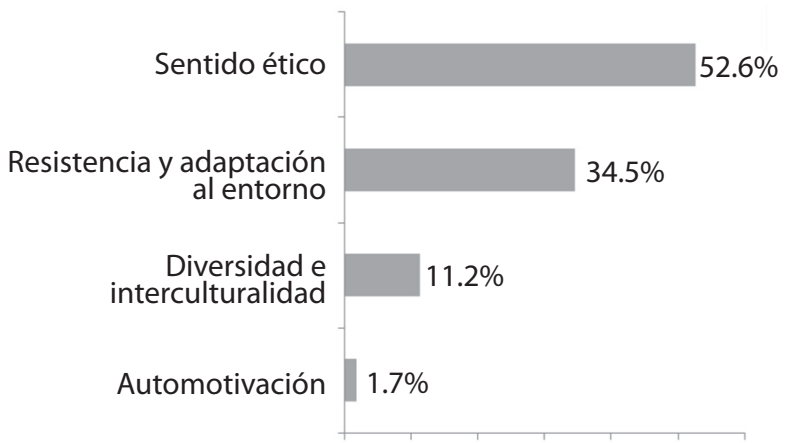

Figura 6. Distribución de competencias individuales que debe presentar el perfil del docente, según opinión de participantes. Fuente: Encuesta a participantes del estudio, 2013.

enfatizaron la necesidad de que el docente del futuro mostrara cualidades que le permitieran un proceder éticamente correcto tanto en su quehacer educativo como personal. Según los participantes del estudio la honestidad, la justicia y la equidad se declaran como valores imprescindibles de los educadores, no solo como elementos claves de su accionar sino como parte de los aspectos a formar entre los estudiantes a su cargo. La incorporación del componente ético en el perfil del docente es fundamental, máxime cuando las sociedades actuales experimentan lo que algunos autores denominan relativismo ideológico y los sistemas sociales muestran signos de desmembramiento del tejido social, crisis de gobernabilidad y altos niveles de corrupción. 
Marina (2006) previene que las morales no bastan pues son sistemas normativos supeditados a determinadas culturas, mientras que la ética es una moral transcultural con capacidad de universalizarse. La ética -esclarece el autor- "es un conjunto de las soluciones más inteligentes que se le ha ocurrido a la humanidad para resolver los problemas que afectan a la felicidad y a la dignidad de la convivencia, los conflictos que puedan surgir entre personas, religiones, culturas, colectivos, naciones diferentes" (Marina, 2006, p. 32).

Las características de la sociedad actual reclaman una formación ética que permita la vivencia y la convivencia dentro un marco de bienestar, de respeto a la dignidad y de desarrollo integral de todos los individuos. Los problemas que enfrentan nuestras sociedades no solo son económicos, sociales, políticos, ideológicos, científicos, tecnológicos sino, sobre todo, éticos. De allí que en la formación de los educadores la competencia de sentido ético tenga un carácter de indispensable e ineludible.

\section{- Competencia resistencia y adaptación al entorno}

De igual manera que el sentido ético, la resistencia y la adaptación al entorno es una de las competencias más mencionadas por los participantes dentro de las competencias interpersonales de la dimensión individual. La resistencia y la adaptación al entorno en las actuales y futuras condiciones sociales emergen como uno de los atributos más importantes que debe caracterizar a los profesionales de la educación. Tal como se ha indicado anteriormente, las nuevas sociedades presentan tendencias de desarrollo altamente complejas (Catalayud, 2008) y difíciles de asimilar tales como la constitución de mega-ciudades con amplia diversidad cultural, las rupturas de bloques políticos, el incremento de la criminalidad y la agudización de fenómenos de exclusión social, entre otros. Este panorama exige que las personas posean las capacidades que les permitan contribuir y atender las demandas sociales, a la vez que cuidar de sí mismas y procurar su propio desarrollo integral.
En el estudio los participantes hacen referencia a la adaptación al entorno mediante expresiones como las siguientes: "adaptación"; "capacidad para saber enfrentar situaciones"; "tener una actitud positiva ante los cambios de la sociedad"; "estar abierto a aceptar cambios"; "ser positivos"; "tener una mente abierta al cambio"; "flexibilidad"; "enfrentar los cambios que la sociedad requiere y formar a los estudiantes para que los afronten".

Además de las menciones sobre una actitud del cambio y adaptación, algunos estudiantes hacen referencia a aspectos relacionados con las habilidades para superar situaciones difíciles, como por ejemplo: "una actitud positiva ante situaciones adversas". En este sentido, el concepto de resiliencia cobra aceptación pues, pese a las discusiones en torno a su definición, es posible que sea el más acertado para la describir el proceder que las generaciones futuras deben asumir para enfrentar la realidad de una sociedad que se presume convulsa, riesgosa, compleja y carente de certezas. En tal sentido, el concepto de resiliencia debería comprenderse como el "ajuste positivo bajo los retos y las condiciones de la vida” (Masten, 2011 citado por Becoña, 2006, p. 138); y no es una condición de seres excepcionales, sino que está presente en personas normales y en variables naturales del entorno inmediato, por eso debe ser una cualidad universal presente en todo tipo de situaciones difícil y contextos desfavorecidos (Vanistaendel, 2002 citado por Uriarte (2013 p. 8).

Finalmente, dentro de las competencias interpersonales de la categoría individual, la competencia diversidad e interculturalidad también fue reconocida por los participantes, con veintiséis menciones. Tal como se ha indicado en este documento al abordar otras competencias, la diversidad e interculturalidad es un elemento crucial, pues las sociedades cada vez más experimentan procesos de reconfiguración a partir de la imbricación de diferentes culturas. Asimismo, la ampliación del abanico de la diversidad y la pluralidad de personas respecto del género, credo, ideología, política, entre otros factores esenciales, exige amplios nivel de respeto, tolerancia, alteralidad, empatía y otros elementos que permitan la construcción de nuevas formas de 
comprender, concebir y crear realidades a partir de lo diverso.

En palabras de Morín (2011), los humanos "requieren reconocerse en la humanidad común y a la vez reconocer la diversidad cultural inherente a todo cuanto es humano" (p. 47). La interculturalidad debe abordarse como un ideal en la formación de los profesionales de la educación y en la educación en general, ya que permite apuntar hacia a la "instauración de relaciones democráticas, a la apertura total y a la igualdad de condiciones entre los actores de la sociedad" (Godenzzi, 1997, p. 2). En consecuencia, se acierta cuando se valora como un elemento necesario en la conformación de un perfil para el docente del futuro.

\section{Competencias interpersonales. Dimensión social}

En cuanto a las competencias interpersonales referidas al ámbito social, la mayoría de las menciones se concentran en la comunicación interpersonal, tal como se observa en la figura 7.

La comunicación interpersonal debe entenderse como el diálogo intersubjetivo circulante ente dos o más individuos. Dentro de este proceso comunicacional, la escucha activa, un elemento lamentablemente poco estimulado en los procesos educativos, juega un papel clave. El concepto de escucha lleva implícita la atención y a la vez una serie de "principios

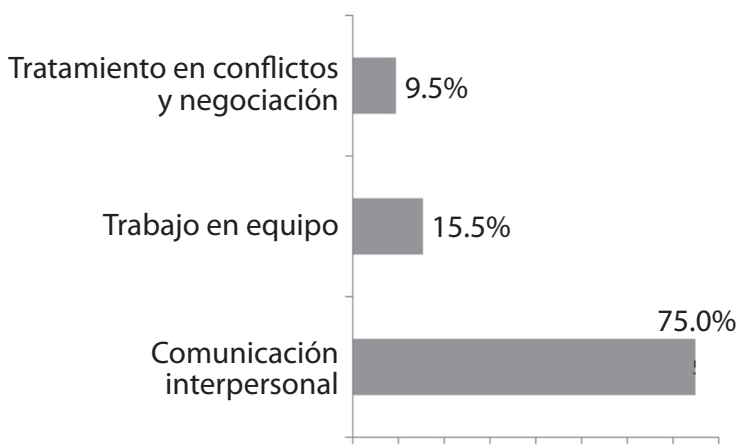

Figura 7. Distribución de competencias de la categoría individual que debe presentar el perfil del docente, según opinión de participantes. Fuente: Encuesta a participantes del estudio, 2013. éticos como la empatía, el respeto (que a veces se contraponen) el no enjuiciar al otro y muchas veces la paciencia" (Castañeda, p. 51).

Con el advenimiento de las TIC, la comunicación interpersonal ha sufrido cambios relevantes, abandonando su condición originaria de efectuarse mediante al copresencialidad de los interactuantes en un espacio y tiempo determinados. Más allá de las oportunidades que las TIC ofrecen para difundir información, existen autores que sostienen que esta modalidad de comunicación mediada por tecnologías de última generación, fracciona normas propias y fundamentales de la comunicación interpersonal y abre espacios a nuevas conductas como la ubicuidad. Antaño, la comunicación interpersonal -cara a cara- implicaba: paciencia, alternabilidad en el diálogo, tolerancia, respeto, atención focalizada, condiciones todas que los nuevos medios de alguna manera estaría depauperando. La amistad como vínculo de afecto hoy se interpreta como contactos digitalizados que se borran en una fracción de segundo. No obstante, la efectividad de la comunicación interpersonal, según otros autores, es un elemento que, en el caso de la comunicación mediada por las tecnologías, puede lograrse cuando los interactuantes experimentan una presencia cognitiva y afectiva en las intercomunicaciones desarrolladas a través de cualquier dispositivo o herramienta tecnológica.

\section{Competencia de trabajo en equipo y tratamiento de conflictos}

En cuanto a la competencia del trabajo en equipo, esta alcanzó 18 de las 1002 menciones. Quiérase o no, las organizaciones bajo la égida de la globalización experimentan transformaciones profundas. La concepción del trabajo tradicional (centrado en los individuos) en la era de la información y el conocimiento exige una nueva estructura: el trabajo en equipo. El recuerdo del científico, el ejecutivo, el investigador o el docente solitario enfrentado a las vicisitudes de su empeño es ahora solo nostalgia. Actualmente, el trabajo en equipo es la principal forma de desarrollo de las organizaciones debido en parte a las demandas que provoca la complejidad de 
esos sistemas y a las exigencias de innovación que proponen los nuevos entornos.

Ante la explosión de la información y el surgimiento de nuevas demandas y tareas, las personas individualmente no están en condiciones de responder efectivamente a todas esas demandas, sino que cada vez más se requiere del trabajo de grupos. En el campo profesional, el trabajo en equipos interdisciplinarios es vital para comprender y abordar los nuevos retos profesionales. De allí la importancia de integrar esta competencia dentro del perfil profesional del docente, tal como lo indicaron los participantes.

En estrecha relación con la competencia analizada anteriormente, el tratamiento de conflictos y la negociación es otra de las competencias que, a juicio de los participantes, debe incluirse dentro del perfil de competencias del docente del futuro.

La confluencia de dos o más personas en el emprendimiento de una tarea común es de por sí, una oportunidad de surgimiento de conflicto, pues las posibilidades de que en la totalidad de las situaciones exista compatibilidad plena entre los interés y opiniones de los involucrados es prácticamente imposible, por tanto el conflicto es consustancial a la interacción humana. No obstante, el conflicto en sí no implica, necesariamente, una situación negativa sino que el meollo del asunto reside en la forma en que se aborde $o$ atienda.

La negoción es la manera más sensata para abordar los conflictos, pues es la vía para lograr una solución en la que prevalezca la simetría entre las partes involucradas. Para Jaca y Medina (2005), los elementos clave de la negociación son: la existencia de una relación de interdependencia entre las partes, una relación motivacionalmente contradictora y relaciones de poder.

El caldo de cultivo de los conflictos es la diversidad de opiniones, criterios, actitudes e intereses. En el perfil de las sociedades emergentes caracterizadas por la creciente diversidad, las posibilidades de surgimiento de conflictos se agudizan. Esto se ve agravado por condiciones socioeconómicas cada vez menos favorables para las mayorías y una ascendente presión por el desarrollo de trabajos colaborativos.
Lo anterior da lugar a un mayor riesgo del surgimiento de conflictos en las diferentes organizaciones sociales, tanto en la esfera pública como privada.

El número de participantes del estudio que se inscriben en esta competencia es limitado. No obstante, la resolución de conflictos y la negoción deben ser consideradas en el perfil docente propuesto para el futuro, en virtud a los beneficios que aporta a la interacción social y al establecimiento de relaciones saludables y productivas.

Esta competencia es además, especialmente importante en los escenarios educativos donde el docente no solamente debe atender las exigencias propias de la enseñanza de determinados contenidos, sino también, en no pocas ocasiones, deberá mediar procesos de negociación entre su estudiantado y permanentemente formar en ellos una cultura de paz y la búsqueda de un desarrollo integral $\mathrm{y}$ armonioso.

En palabras de los participantes el docente del futuro debe: "tener habilidad para manejar situaciones problemáticas en el aula"; "comunicación necesaria para resolver conflictos".

\section{Clasificación competencias sistémicas}

En la totalidad de la clasificación sistémica, el estudio determinó que las competencias más valoradas por los participantes son la actualización continua, la creatividad, la innovación y el liderazgo, tal como se observa en la figura 8 .

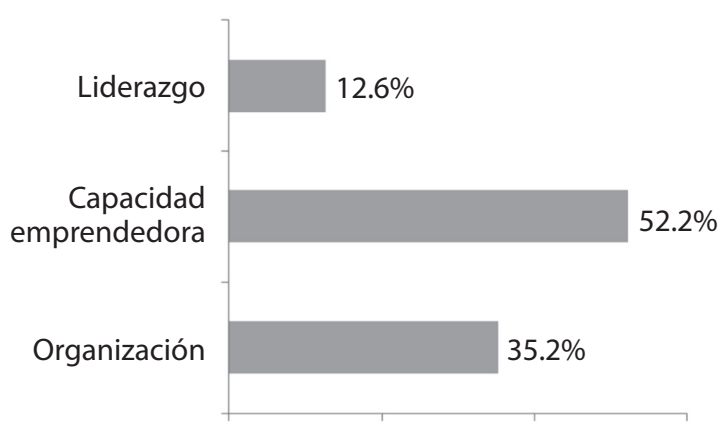

Figura 8. Distribución de competencias sistemas, según clasificación que debe presentar el perfil del docente, conforme opinión de participantes. Fuente: Encuesta a participantes del estudio, 2013. 


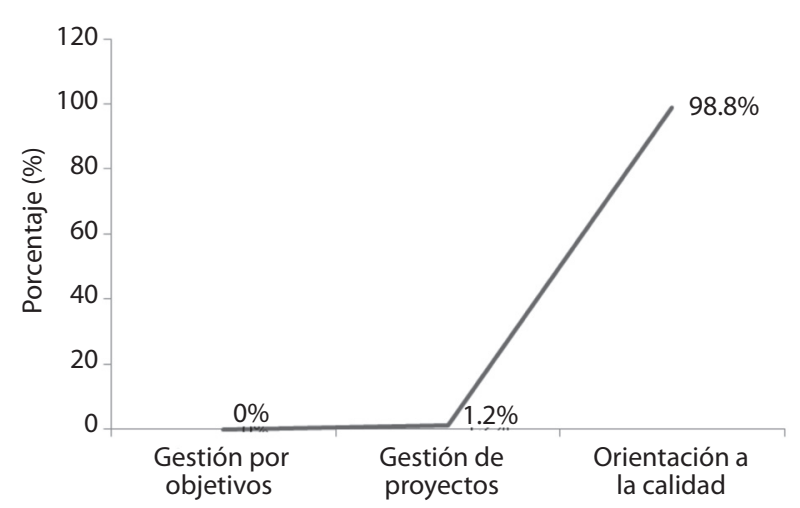

Figura 9. Distribución de competencias correspondientes a la categoría "organización” propuesta por los participantes para la construcción del perfil docente. Fuente: Encuesta a participantes del estudio, 2013.

En la clasificación "sistémicas" la categoría "organización" registra el segundo lugar de importancia de competencias citadas por los participantes del estudio. El mayor porcentaje de citación ocurre en las competencias incorporadas a la categoría "capacidad emprendedora" y en su interior se destaca la competencia "creatividad".

Dentro de las competencias sistémicas, aquellas referidas a la organización son las que ocupan un segundo lugar de importancia para los participantes del estudio y dentro de ellas la que alcanza mayor cantidad de menciones es la "actualización y capacitación”, tal como se visualiza en la figura 9.

En la sociedad de la información y el conocimiento, la competencia "actualización continua" se manifiesta como una previsión indispensable para mitigar la obsolescencia del conocimiento. La valoración con 80 menciones que expresaron los participantes en el estudio, pareciera aludir acertadamente a una importante intuición prospectiva, con respecto a la formación continua. Actualmente, y en un futuro mucho más exigente, será inconcebible pretender que la formación inicial otorgada por una institución formadora de docentes sea suficiente para asegurar el adecuado desempeño profesional durante toda la vida laboral. Algunos de los indicadores aportados por los participantes del estudio en el afán de justificar esta competencia son: "apertura a la capacitación"; "autoformación"; "deseos de mejorar y actualización de la información"; "formación constante en su área"; "desarrollo de la potencialidad para estar constantemente actualizándose"; "actitud de constante capacitación y actualización de acuerdo a los cambios sociales"; "actualizarse en su especialidad porque el mundo cambia constantemente"; "conocimiento, interés por aprender así como formación constante de acuerdo a las expectativas del mundo actual".

En la contemporaneidad no existe conocimiento permanente. Werner Jaeger, citado por Bauman (2005) pensó que el concepto de pedagogía y aprendizaje había surgido de dos supuesto básicos: “ La idea de que debajo del desmenuzable estrato de diversidad de la variable y cambiante experiencia humana se asienta la roca del orden inmutable del mundo; y, las leyes que sustentan y gobiernan la naturaleza humana son igualmente sólidas” (p.32). En la actualidad la "explosión cámbrica del conocimiento" borró tales supuestos, que otrora dieron origen a la educación. La obsolescencia del conocimiento demanda de los profesionales - y de todo aquel que pretenda sobrevivir en la era de la explosión de la información- la atención constante y responsable de su propio desarrollo profesional.

\section{- Competencia capacidad emprendedora}

En cuanto a la categoría capacidad emprendedor, las menciones se concentran fundamentalmente en las competencias creatividad y la innovación, en contraposición con el espíritu innovador sobre el cual no se realiza ninguna mención. El desglose de las menciones realizadas por los participantes se refleja en la figura 10.

\section{- Competencia creatividad}

La creatividad entendida como "la capacidad de abordar y responder satisfactoriamente a situaciones de forma nueva y original en un contexto dado" (Villa y Poblete, p. 262) es una de las competencias que deben ser consideradas dentro del perfil de 


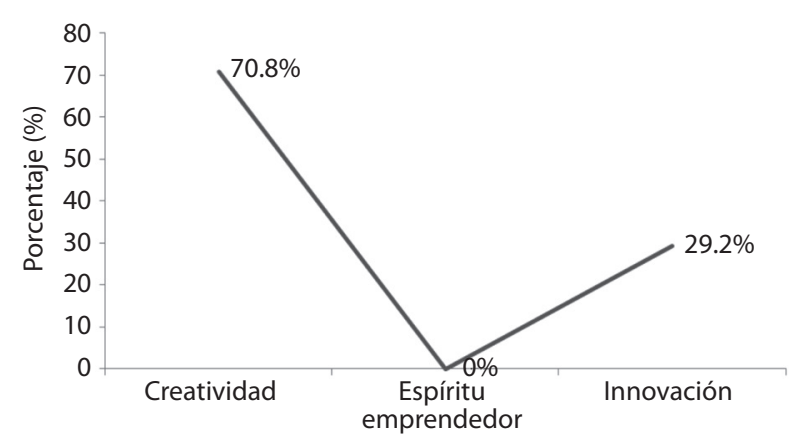

Figura 10. Distribución de competencias referidas a la capacidad emprendedora que debe presentar el perfil del docente, según opinión de participantes. Fuente: Encuesta a participantes del estudio, 2013.

docente del futuro, ya que como lo plantea De Bono (2011), la creatividad es la que da pie al progreso en todos los campos del saber y de la vida en general.

En el estudio realizado, la creatividad obtuvo 85 de las 1002 menciones brindadas por los participantes. Algunas de las menciones indicadas son las siguientes: "creatividad para desarrollar métodos educativos"; "capacidad creativa para impartir lecciones"; "permitir el aporte creativo de los estudiantes"; "fomentar en el estudiante la creatividad"; "implementar herramientas educativas para la creatividad"; "fomentar en el estudiante la creatividad".

Como puede observarse, las frases utilizadas por los participantes no solo apuntan a la necesidad de que el docente sea creativo, sino de que desarrolle esta competencia en el estudiantado a su cargo. En consecuencia, la incorporación de la creatividad dentro del perfil del docente es clave, pues existe bibliografía que valida la tesis de que la creatividad es factible de enseñarse y aprenderse en entornos académicos (Marín y Martín; 2012; p. 349). En este sentido, es necesario establecer la diferencia entre la creatividad artística y la creatividad de ideas De Bono (2011); el primer concepto alude al talento innato, mientras que el segundo se refiere a una facultad que se puede enseñar de manera tan formal como cualquier contenido.

\section{- Competencia innovación}

La otra competencias sistémica mencionada por los participantes fue la innovación aunque con solamente 35 menciones. La innovación en este estudio se comprende como la respuesta satisfactoria a las necesidades y demandas personales, organizativas y sociales, modificando o introduciendo elementos nuevos en los procesos y en los resultados (Villa y Poblete, 2008, p. 276).

La innovación está estrechamente relacionada con la creatividad, pues la primera requiere de la segunda para implementar exitosamente las ideas creativas dentro de los sistemas organizacionales. Es decir, la innovación es la imbricación satisfactoria de una idea creativa dentro del sistema instaurado.

La competencia innovación es indispensable en el quehacer educativo porque permite aprovechar los avances y experiencias de los diferentes campos del saber para aportar a la mejora de las prácticas pedagógicas y de los aprendizajes. La extrapolación de ideas, de metodologías y de teorías al campo educativo es parte de los retos que los educadores deben atender para mejorar progresivamente el desempeño profesional y responder a las necesidades y demandas en una sociedad altamente cambiante y sobresaturada de información. Es mediante la innovación que será posible posicionar a la educación en un lugar que permita vincular los avances científicos y tecnológicos para generar a beneficios significativos en el campo educativo.

\section{- Competencia liderazgo}

Con respecto a la clasificación sistémica, la competencia liderazgo únicamente obtuvo 29 menciones, entre las que destacan los siguientes enunciados "liderazgo en la vida personal y profesional"; "actitud de triunfador y líder"; "liderazgo y guía en el proceso de enseñanza".

Según la definición de Villa y Poblete (2008), el liderazgo es la capacidad de influir sobre los individuos o grupos anticipándose al futuro. Es valioso para los docentes poseer los atributos que le 
permitan ejercer liderazgo en el campo educativo y en los contextos específicos en los que se desempeña como docente. El liderazgo en el ejercicio de la docencia, según Bolívar (2011), consiste esencialmente en desarrollar la capacidad de los estudiantes para que se involucren en un buen aprendizaje y desarrollen al máximo sus potencialidades.

El liderazgo moderno desecha la vieja tesis de ordenar, controlar, supervisar y predecir. En la actualidad el liderazgo significa implicar, motivar y animar a las personas para alcanzar lo mejor de sí mismas en las tareas asignadas (Bolívar, 2011). Por tanto, el ejercicio de liderazgo demanda un sentido de alteralidad, es decir comprender al otro y el compromiso de participar positivamente en el desarrollo integral de ese otro. Asimismo, el liderazgo reconoce la interdependencia entre las personas y la necesidad de un liderazgo distribuido, en el que se abran oportunidades para la creación y fortalecimiento de capacidades de las personas de liderar incluso sus propios procesos educativos. Es en el contexto de esta apreciación que el liderazgo, como competencia genérica, se manifiesta necesario para completar, de algún modo, un perfil profesional para el docente del futuro.

Como ha podido observarse, los participantes consideran que las categorías de competencias más importantes para la construcción de un perfil docente del futuro son las relacionadas con el uso de TIC, el sentido ético, la orientación al aprendizaje y las relaciones interpersonales. Sorprendentemente las competencias cognitivas y ligústicas son subvaloradas pese a su relevancia en los procesos educativos. De tal suerte que el perfil para el profesional docente del futuro, desde la percepción de los participantes, podría representarse en la figura 11.

\section{DISCUSIÓN DE RESULTADOS}

La imperiosa necesidad de anticipar el futuro está ubicada en los lóbulos frontales del ser humano, en el cerebro ejecutivo; es parte de la condición humana. Pensar en el porvenir, organizarlo, elaborar planes y proponer metas es una de las necesidades vitales del ser humano. Esto es así, a pesar de la casi imposibilidad de acertar predicciones, en una

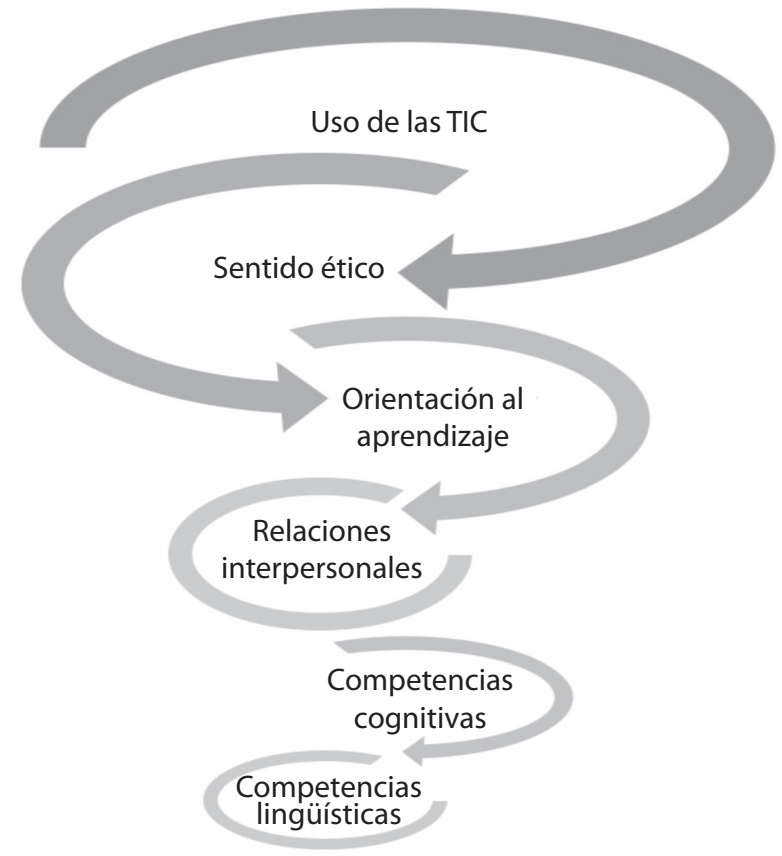

Figura 11. Principales competencias identificadas por los participantes para el docente del futuro. Fuente: Elaboración propia a partir de opiniones expresadas por participantes del estudio, 2013.

sociedad cambiante caracterizada por la incertidumbre, el riesgo; la aceleración del tiempo; la obsolescencia del conocimiento; un desarrollo científico y tecnológico exponencial y una explosión de la información, que ocurre en todos los ámbitos del saber humano y en todo momento.

Es justamente en ese contexto, y con las limitaciones del caso, que en este estudio se intenta construir respuesta a la interrogante: ¿cuáles competencias deberán acompañar a los docentes en formación de cara al futuro? En ese afán se logran identificar las cuatro competencias que los participantes consideran más importantes, entre las cuales el uso de las tecnologías de la información y la comunicación ocupan un lugar preponderante e, incluso, duplican las menciones a la competencia "sentido ético", que es la más cercana en citaciones.

No es sorpresa este resultado, pues el surgimiento de las TIC en la sociedad ha generado una total conmoción, al extremo de que ha permeado todas las esferas de la actividad humana. A nivel 
puramente de convivencia social, ha cambiado las formas y maneras de relacionarse, de socializar, de comunicase. En los procesos de enseñanza, está desplazando al libro como receptáculo de contenidos. La presencia in situ del docente, al paso que avanzan las tecnologías, corre el riesgo de convertirse en nostalgia. Esta feroz inserción de las TIC en el campo educativo, augura para el futuro propuestas cismáticas que revolucionarán las tradicionales formas de enseñanza y aprendizaje.

Las tecnologías de medios, históricamente, en la educación y en las primeras etapas de su desarrollo, se han abordado como panaceas, un remedio con capacidad para sanar todos los problemas que presenta la educación. Algo así ocurrió en su momento con la incursión de la radio, el teléfono y la televisión; en ese entorno se habló de que su generalidad y relativo fácil acceso democratizaría los procesos de enseñanza. No obstante, esa promesa no se cumplió en su totalidad, pese a que permitió avances importantes en la transmisión del discurso educativo. La UNED no estuvo exenta de esa realidad, como tampoco lo es hoy con las TIC.

La inclinación de los participantes hacia las competencias relacionadas con el uso de las TIC plantea la interrogante de si realmente la incorporación de esas tecnologías en la educación vendría a marcar diferencias. Coll, Monereo y Martí (2008) declaran que estos medios, en su formato actual, "tienen una especial importancia porque afectan a prácticamente todos los ámbitos de la actividad de las personas, desde las formas y prácticas de orden social, hasta la manera de comprender el mundo, organizar esa comprensión y transmitirla a otras personas. Las TIC han sido siempre, en sus diferentes estados de desarrollo instrumentos para pensar, aprender, conocer, representar y transmitir a otras personas y otras generaciones los conocimientos adquiridos" (Coll y Monereo, 2008; Coll y Martí, 2001, p. 22). Pese a esta esperanzadora expectativa, existen voces discordantes que manifiestan sus críticas. No obstante, en materia de "medios" la crítica siempre será válida, eso sí, entendiendo este argumento como la actitud y capacidad de discernir lo positivo y negativo de una cuestión.
Una de estas voces proviene de mediados de la década de los 60 del siglo pasado, y su estruendo acuñado en un célebre aforismo aún hace eco en los estrados académicos: "el medio es el mensaje". Esta frase de McLuhan debutó por vez primera en su obra Comprender los medios de comunicación $\mathrm{y}$, de una $\mathrm{u}$ otra forma, revolucionó el debate y comprensión de los medios, colocando en un extremo los entusiasta y en el otro los detractores. McLuhan entendió los medios como extensiones, sea ya de una habilidad o facultad humana. La sentencia "el medio es el mensaje" nos alerta en concordancia con su pensamiento de que a largo plazo el "medio" con su empleo insistente se empodera del mensaje y pasa a ser en sí mismo el mensaje. Esta condición de los "medios" es un tema de obligada exploración, cuando se proponen por parte de educadores metodología didáctica para mediar contenido empleando como vehículos de transmisión instrumentos como las TIC.

Las tecnologías de medios, en los procesos de enseñanza aprendizaje, no median didácticamente, por sí solas, los contenidos académicos. La labor de mediación pedagógica es una tarea que solo puede realizar el docente y, por tanto, es ineludible la responsabilidad de los profesionales de la educación no solo comprender las implicaciones del uso de las tecnologías sino también reconocer los límites que esos medios conllevan en cuanto a la vehiculización de los contenidos.

Las tecnologías no gozan de un fuero de neutralidad, por ahí se condujo el discurso de MacLuhan. El debate sobre la neutralidad de los medios es de larga data y sus principales protagonistas se atrincheran entre el determinismo tecnológico y el instrumentalismo. No obstante, más allá de ese debate, la incorporación de las tecnologías al quehacer educativo implica necesariamente que el docente tenga conciencia de que las tecnologías de medios, en la era de la información y el conocimiento, son valiosos recursos para transmitir contenidos, pero por sí mismos no son suficientes para el desarrollo de procesos de aprendizaje, pues no conllevan implícitamente la mediación pedagógica. La mediación pedagógica a través de medios es precisamente donde deben concentrarse los esfuerzos para el mejor aprovechamiento de estos recursos, no solo para 
enriquecer los procesos de aprendizaje sino incluso para potenciar cambios significativos en cuanto a las competencias cognitivas de las personas.

En la historia de la humanidad, las tecnologías de medios casi siempre han provocado suspicacia. Una de las revoluciones tecnológicas de medios más espectaculares, fue la invención del alfabeto fonético por parte de los griegos, "hazaña que poco a poco fue erosionando el uso de sus muy preciados dones retóricos y memorísticos y dio pie a nuevos recursos cognitivos que continúan formándonos en la actualidad" (Wolf, 2008, p.79). No obstante, Sócrates (470-399ac.) se permitió poner en duda esa tecnología que hoy es imprescindible.

Sócrates postulaba que la lengua hablada y la escrita desempeñaban un papel diferente en la vida intelectual del sujeto; en segundo lugar, consideraba que las nuevas -y mucho menos rigurosas- exigencias de la lengua escrita colocaban tanto la memoria como la interiorización del conocimiento en una situación catastrófica... (Wolf, 2008, p. 93).

Según Wolf (2008), las objeciones más importantes por las que Sócrates desdeña la escritura fueron: la rigidez de la lengua escrita, la destrucción de la memoria y la pérdida de control sobre el lenguaje. El tiempo demostró lo infundado de esos socráticos temores. Hoy los mismos temores sobre la aprehensión del conocimiento emergen- como en los tiempos de los diálogos de Sócrates y Platón- pero esta vez en la disyuntiva de una cultura lecto- escritural a una cultura digital-visual.

Es precisamente en el contexto de esta emergente cultura digital-visual en la que se presentan nuevas voces disonantes, cuyas objeciones, por su estrecha relación con los procesos educativos, sería necesario considerar. Entre ellas se destacan: el uso de las TIC está modificando la forma y el fondo de cómo tradicionalmente se ha abordado la lectura; la exposición de los infantes durante los primeros años de vida a medios digitales podría afectar su desarrollo natural; el depauperamiento de importantes competencias cognitivas ocurre como consecuencia del reiterado uso de la internet, entre otras ideas.

Las manifestaciones en torno a los cambios originados por la cultura digitovisual trascienden el razonamiento intuitivo y patentan nuevas informaciones dignas de considerar en el mundo de la educación. Nicholas Carr (2010) refiere a investigaciones llevada a cabo por Jakob Nielsen (2006), entre los usuarios de la RED, en la que se determinó "que casi ninguno de los participantes leía el texto en pantalla de manera metódica, línea por línea, como se lee las páginas de un libro impreso. La inmensa mayoría de ellos echaba una rápida ojeada con la que escaneaba la pantalla en un patrón que seguía el trazo de la letra F” (p. 166). Algunos investigadores definen esta modalidad como una lectura de saltos.

Según esas investigaciones, como consecuencia de cultura digito-visual, se ha producido una variación en el patrón de lectura. Es decir el patrón lineal, típico de la cultura occidental, de izquierda a derecha o al contrario, se está modificando por una práctica de lectura vertical. Esta modificación del patrón de lectura por parte de los usuarios de la web posiblemente tendrá consecuencias en el orden de las competencias cognitivas.

Otros estudios respecto de los cambios acarreados por la cultura digito-visual se refiere a las facultades cognitivas. Según Patricia Greenfield (2009) citada por Carr (2010) luego de un análisis de 50 estudios referentes a estos medios, la "nueva riqueza en inteligencia visual espacial va de la mano con el debilitamiento de las capacidades para el tipo de "procesamiento profundo" en el que se basa la "adquisición consciente de conocimiento, el análisis inductivo, pensamiento crítico, la imaginación y la reflexión.” (p. 173).

Por otra parte, L'Ecuyer (2012), con respecto a los efectos de las tecnologías de medios en el caso de los niños, indica que la Academia Americana de pediatría "recomienda evitar que los niños vean pantallas hasta los dos años por considerar que los estudios apuntan a que se produce más efectos negativos que positivos" (p.42).

Si de lo que se trata es de la preocupación de los padres por potenciar la inteligencia de los infantes, Dan Siegel (2001) citado por L'Ecuyer (2012), advierte que la "sobreproducción de conexiones sinápticas durante los primero años de vida es suficiente en sí para que el cerebro pueda desarrollarse 
adecuadamente dentro de un entorno medio que proporciona la cantidad mínima de estimulación sensorial..." (p.43). La sobreestimulación impulsada por los medios como las TIC es un fenómeno social que ha comenzado a preocupar a docentes, padres de familia y autoridades educativas, en razón de los efectos que estos medios ocasionan en el aprendizaje. L'Ecuyer (2012) informa, citando a Chistakis (2004) que: "existen estudios que relacionan las horas de televisión durante la infancia con el riesgo de presentar problemas relacionados con la atención y trastornos de aprendizaje, con una disminución del interés del alumno en el aula..." (p. 51).

El avance hacia una cultura digito-visual es inevitable. La humanidad, a riesgo de tropezar en un reduccionismo, tiende a polarizarse entre los que aprueban las experiencias del pasado sin cuestionamiento y los que reclaman la novedad y el cambio sin restricción. La crítica como argumento de ponderación debe necesariamente estar presente en el abordaje de temas tan vitales como este para no incurrir en los extremos.

¡Las tecnologías son extensiones!, nos recuerda McLuhan: no hay neutralidad en ellas, su uso reiterado e incorporado a la cultura bien podría reestructurar la "circuitería" de nuestro cerebro, en busca de una mejor y más eficiente adaptabilidad al medio. He ahí la plasticidad neuronal del cerebro que activa nuevos circuitos, para provocar nuevas funciones en busca de la eficiencia y ralentiza otras que inevitablemente se degrada con el transcurrir del tiempo por su falta de uso. Pero es precisamente en este intríngulis donde a la educación le cabe una importante responsabilidad, determinando, valorando, investigando cuáles competencias cognitivas basales podrían realmente estar erosionándose como consecuencia del desarrollo de los procesos de enseñanza aprendizaje en el contexto de la cultura digito-visual.

La reflexión en torno a las competencias sobre uso de las TIC devela un cambio en el paradigma cultural, en el periplo de una cultura lectoescritural a una cultura digitovisual: la era del soporte inmaterial de los contenidos culturales. El libro, el disco compacto, el DVD, las películas en $35 \mathrm{~mm}$, las revistas de divulgación, han sido desprovistos de su soporte material; y se han digitalizado. Los contenidos académicos para la instrucción, formación y educación, prioritariamente, son preservados y divulgados en soportes inmateriales. Estamos asistiendo ya como actores o espectadores a la transición de una cultura lectoescritural que data aproximadamente del 750 a.C., a una cultura digitovisual que parece no convenir con la "materialidad". No es un cambio inocuo, sin trascendencia ni repercusiones. Este cambio implica, desde el punto de vista educativo, replantear competencias tales como las cognitivas, lecto-escriturales, de aprendizaje, de relaciones interpersonales, éticas, que desde ya están siendo cuestionadas en su condición convencional.

No solo los contenidos visuales, sonoros o escriturales han abandonado el soporte material. Las relaciones interpersonales, una de las manifestaciones más primarias que ha permitido la constitución de la sociedad, al paso que avanza la cultura digitovisual están perdiendo su condición de contigüidad, de diálogo cara a cara, con todas las implicaciones emocionales que este acto tan significativo expresa. En una cultura digitovisual casi todo se desplaza online, hasta el mercado de emparejamiento y otras tantas relaciones de índole interpersonales. Las redes sociales con sus Twitter, Facebook, WhatsApp y sus exigencias en la visión focalizada, la multi-atención, están forjando una nueva gramaticalidad del discurso escrito con el propósito de adecuarlo a las imposiciones del medio. La conectividad constante a las redes sociales para los "nativos" y "migrantes" es un imperativo. ¡Me conecto en las redes sociales, LUEGO SOY!

Quizá en la aldea global, cuya construcción fue favorecida por las tecnologías de la comunicación e información, y en esa contigüidad video digital en que cohabitan las diferentes culturas en el mundo, en un futuro no muy distante, exista la posibilidad de una resignificación y trascendencia desde morales particulares hacia una ética de carácter universal que dé cuenta de asuntos cruciales como el concepto de vida, dignidad humana, del biocentrismo antes que el antropocentrismo, una ética en primer lugar laica, es decir, deslindada de dogmas de cuños religiosos y de verdades legitimadas científicamente. 


\section{CONCLUSIONES}

De las 35 competencias propuestas en el sistema de clasificación de Villa y Poblete (2008), se analizaron 15 competencias que alcanzaron niveles significativos de menciones, según la norma establecida para el estudio. No obstante, los participantes debieron señalar las cuatro competencias que ellos consideraron esenciales para el docente del futuro siendo el uso de las tecnologías, el sentido ético, la orientación al aprendizaje y la comunicación interpersonal las que en orden de importancia alcanzaron mayor número de menciones.

Los participantes en el estudio subestimaron competencias basales para el desarrollo de conocimientos tales como las competencias cognitivas y las lingüísticas.

La construcción de un perfil profesional a partir de la opinión de los participantes presenta una desproporción alarmante, especialmente entre las competencias referidas al uso de las TIC y las cognitivas, por ejemplo, en donde la razón de menciones entre una y otra es mayor a 11.

De acuerdo con los datos obtenidos en el estudio, parece necesario realizar una revisión del proceso formativo y de los planes de estudio cursados por los participantes con el propósito identificar los cambios requerido para que los estudiantes incorporen las competencias lingüísticas y cognitivas como elementos fundamentales en el perfil y en el quehacer del docente del futuro.

\section{REFERENCIAS}

Bauman, Z. (2008). Los retos de la educación en la modernidad líquida. Barcelona: Editorial Gedisa, S.A.

Calatayud, M. (2008). La escuela del futuro. Hacianuevos escenarios. Madrid: Editorial CCS.

Carr, N. (2011) ¿Qué está haciendo internet con nuestras mentes superficiales? España: Santillana Ediciones Generales, S.L.
Castañeda, M. (2011). ESCUCHAR (NOS) Hacia la comprensión de los demás y de uno mismo. México: Santillana Ediciones Generales, S.A.

Darder, M. (2003). Sedúcete para seducir. Vivir y educar las emociones. Barcelona: Ediciones Paidós Ibérica, S.A.,

De Bono, E. (2011). PIENSA. Antes de que sea demasiado tarde. Madrid: Impreso en talleres Brosmac, S.L.

Fernández, C. y Salinero, M. (2006). Las competencias en el marco de la convergencia europea: un nuevo concepto para el diseño de programas educativos. Encuentros en teoría e historia de la educación. 6, 2006. Pp. 131-154. Recuperado de http://library. queensu.ca/ojs/index.php/encounters/article/ view/603

Fregoso, G. (2010). Diagnosis sobre habilidades lectoescriturales de estudiantes en el Centro Universitario de Los Altos. Revista de la Red de Universidades Lecotras Álabe. 1, 2010. Pp 1-20. Recuperado de http://www.ual.es/alabe.

Gazzaninga, M. (2006) El cerebro ético. Barcelona: Ediciones Paidós Ibérica, S.A.

Godenzzi, J. C. (1997). Equidad en la diversidad reflexiones sobre la educación intercultural en los Andes y la Amazonía. TINKUY Sección de Estudios Hispánicos No 1 - 2005. Recuperado de http://dialnet.unirioja.es/...ga/articulo/3302998.pdf

Hawes, G. (2003). Pensamiento crítico en la formación universitaria. Universidad de Talca.

Jaca, L.M. y Medina, F. (2005). Gestión del conflicto, negociación y mediación. España: ediciones Pirámide.

Jensen, E. (2010). Cerebro y aprendizaje. Competencias e implicaciones educativas. Madrid: Narcea.

Macluhan, M. (1996). Comprender los medios de comunicación. Las extensiones del ser humano. Barcelona: Paidos.

Magendzo, A. (1991) ¿Superando la racionalidad instrumental? Ensayos en busca de un nuevo paradigma para la educación y la discusión de los derechos humanos. Santiago: Impresos S.A.

Marina, J. (2006). Aprender aconvivir. Barcelona: Editorial Ariel, S.A. 
Morín, E. (2009). La cabeza bien puesta. Repensarla reforma. Reformar el pensamiento-1ed., reimp. Buenos Aires: Nueva Visión. Argentina.

Morín, E. (2011). Los siete saberes necesarios para la educación del futuro. -1ed., 6ª reimp. Buenos Aires: Nueva Visión. Argentina.

Pozo, J. y Pérez M. (2009) Psicología del aprendizaje universitario: la formación en competencias. Madrid: Ediciones Morata, S.L.
Rodríguez, M. L.; Serreri P. y Del CimmutoA. (2010). Desarrollo de competencias: teoría y práctica. Balance, proyecto profesional y aprendizaje basado en el trabajo. Barcelona: Laertes Educación

Villa, A. y Poblete M. (2008) Aprendizaje basado en competencias. Una propuesta para la evaluación de las competencias genéricas. -2-ed. España: Ediciones mensajero, S.A.U.Bilbao.

Zabala, Antoni y Arnau, Laia. (2010). 11 ideas clave. Como aprender y enseñan competencias. Barcelona: 3 Grao. 
